\title{
Reducing geological uncertainty by conditioning on boreholes: the coupled Markov chain approach
}

\author{
Amro M. M. Elfeki • F. M. Dekking
}

\begin{abstract}
The CMC (coupled Markov chain) model, which is based on the extension of Markov chains in twodimensions, is used in the reduction of uncertainty in geological structures when conditioned (i.e., honours the data and their location) on a number of boreholes. The model has been applied to an unconsolidated aquifer deposit located in the central Rhine-Meuse delta (the Gorkum study area) in the Netherlands. A comparison is also made between the CMC and the SIS (sequential indicator simulation) model, which is based on Kriging and co-Kriging theories on the same deposit. The results show the potential applicability of the CMC model in reducing the uncertainty in geological configurations when a sufficient number of boreholes is available. Reproduction of the global geological features requires relatively few boreholes (in this case study, nine boreholes with $30-\mathrm{m}$ spacing over a distance of $240 \mathrm{~m}$ ). However, reproduction of the proportion of each state requires a relatively large number of boreholes (in this case study 31 boreholes with 8 -m spacing over a distance of $240 \mathrm{~m}$ ). It has been shown
\end{abstract}

Received: 13 March 2006 / Accepted: 27 April 2007

Published online: 22 June 2007

(C) Springer-Verlag 2007

Amro M. M. Elfeki on leave from Department of Irrigation and Hydraulics, Faculty of Engineering, Mansoura University, Mansoura, Egypt

\section{A. M. Elfeki (ه)}

Water Resources Section,

Faculty of Civil Engineering and Geosciences, Delft University of Technology,

P.O. Box 5048, 2600 GA, Delft, The Netherlands

e-mail: elfeki_amr@yahoo.co.uk

F. M. Dekking

Department of Applied Probability and Statistics,

Faculty of Electrical Engineering,

Mathematics and Computer Science, TU Delft,

P.O. Box 5031, 2600 GA, Delft, The Netherlands

e-mail: F.M.Dekking@math.tudelft.nl

Present address:

A. M. Elfeki

Department of Water Resources, Faculty of Meteorology,

Environment and Arid Land Agriculture,

King Abdulaziz University,

P.O. Box 80208, Jeddah, 21589, Saudi Arabia that variograms can be deceptive in modeling the spatial pattern and that they reflect only part of the complete spatial structure in the field. The use of transition probabilities via the CMC model provides a better alternative approach, because it uses multiple point information.

Résumé Le modèle CMC (chaîne de Markov combinée), basé sur l'extension à deux dimensions des chaînes de Markov, est utilisé pour la réduction des incertitudes au niveau des structures géologiques lorsqu'elles sont conditionnées sur un nombre de puits (nécessite des données et leur localisation par exemple). Le modèle a été appliqué à un dépôt aquifère non-consolidé localisé dans le centre du delta Rhin-Meuse (la zone d'étude Gorkum) aux Pays-Bas. Une comparaison est aussi effectuée entre le modèle CMC et le modèle SIS (Simulation par Indicateur Sequentiel) qui est basé sur des théories de Krigeage et de co-Krigeage pour ce même dépôt. Les résultats montrent l'application potentielle du modèle CMC pour la réduction des incertitudes au niveau des configurations géologiques lorsqu'un nombre suffisant de puits est disponible. La reproduction des caractéristiques géologiques globales demande relativement peu de puits (neuf puits distants de $30 \mathrm{~m}$ sur une distance de $240 \mathrm{~m}$ pour cette étude). Cependant, la reproduction de la proportion de chaque situation demande un nombre relativement important de puits (31 puits distants de $8 \mathrm{~m}$ sur une distance de $240 \mathrm{~m}$ pour cette étude). Il a été montré que les variogrammes peuvent être décevants pour modéliser les caractéristiques spatiales et qu'ils reflètent uniquement une partie de l'entière structure spatiale du terrain. L'utilisation des probabilités de transition à travers le modèle CMC fournie une approche alternative meilleure car elle est basée sur l'information de multiples points.

Resumen El modelo CMC (Cadena de Markov Acoplada), el cual se basa en la extensión de cadenas de Markov en dos dimensiones, se ha usado en la reducción de incertidumbre en estructuras geológicas cuando se ha acondicionado en varios sondeos (ie aportado los datos y su localización). El modelo se ha aplicado a un depósito acuífero no consolidado que se localiza en el delta central Rhine-Meuse (el área de estudio Gorkum) en los Países Bajos. También se hace una comparación entre el CMC y el modelo SIS (Simulación Indicadora Secuencial) el cual se basa en las teorías de Kriging y co-Kriging del mismo depósito. Los 
resultados muestran la aplicabilidad potencial del modelo $\mathrm{CMC}$ para reducir la incertidumbre en configuraciones geológicas cuando está disponible un número suficiente de sondeos. La reproducción de las características geológicas globales requiere un número relativamente menor de sondeos (en este estudio de caso nueve sondeos con espaciado de $30 \mathrm{~m}$ en una distancia de $240 \mathrm{~m}$ ). Sin embargo, la reproducción de la proporción de cada estado requiere un número relativamente grande de sondeos (en este estudio de caso 31 sondeos con espaciado de $8 \mathrm{~m}$ en una distancia de $240 \mathrm{~m})$. Se ha mostrado que los variogramas pueden ser engañosos al modelizar el patrón espacial y que sólo reflejan parte de la estructura espacial completa en el campo. El uso de probabilidades de transición mediante el modelo CMC aporta un mejor enfoque alternativo debido a que usa información de puntos múltiples.

Keywords Coupled Markov chains - Geostatistics · Heterogeneity - Conditioning - Uncertainty quantification

\section{Introduction}

Characterization of subsurface heterogeneity is essential in many engineering fields such as hydrogeology, oil and mining industry and civil and geo-technical engineering. The information obtained about subsurface formations often comes from boreholes. Boreholes provide sufficient knowledge about the vertical variability (i.e., sequence of facies, beds and rock types) of the depositional environments - e.g., from cone penetration test (CPT) data, core and texture analysis, multi-level sampling of soil properties etc. In the 1960s, there were early attempts to apply Markov chains in geology to synthesize a stratigraphic sequence in the vertical direction (Krumbein 1967). However, this approach was not directed towards extension to multidirections. It was abandoned for a few years because of its limited applications in real field situations. Elfeki (1996) developed a methodology to characterize subsurface heterogeneity based on a two-dimensional extension of the one-dimensional Markov chain theory. This model is called the coupled Markov chain (CMC) model. It is general in the sense that it is capable of producing a variety of heterogeneous patterns that can be stationary or non-stationary in a statistical sense; however, the approach assumes stationarity of the single-step transition probabilities.

"Conditioning" is the process of honouring data and their locations in the associated boreholes. A shortcoming of the initial model is that conditioning on more than one borehole is not possible. This limitation has been overcome by Elfeki and Dekking (2001). The CMC model has been applied with success to two-dimensional cross-sections of synthetic formations, on real outcrops in Spain (Elfeki and Dekking 2001), on borehole data at the MADE (macrodispersion experiment) site in Mississippi, USA-Elfeki and Rajabiani (2002), and extended by Elfeki (2006a) on the same site - on CPT data (Elfeki and Dekking 2005), and on a geological map of the alluvium structure at the
Gorkum study area in the Netherlands (Elfeki (2006b)) for contaminant transport simulation and the effect of conditioning on concentration distribution and its moments.

Li et al. (2004) have extended the CMC model to a socalled "triplex Markov chain" (TMC) for modelling the spatial distribution of soil classes in the horizontal plane conditioned on survey lines defined over a grid. Later, Zhang and Li (2005) applied the TMC for modelling multinominal land-cover classes of the Lunan Stone Forest National Park, China, which are derived from IKONOS satellite imagery. Park et al. (2003) have extended the CMC model to three-dimensions, however, this model is not yet fully developed.

There are other approaches that use Markov chains in geostatistics, (e.g., Carle and Fogg 1996, 1997). In these approaches, the authors use Markov chains in three dimensions and link the transition probability with the classical geostatistical theory. The methodology has been applied on the Kings River alluvial fan (USA) by Weissmann et al. (1999) and Weissmann and Fogg (1999), and applied also by Proce et al. (2004) on the buried valley aquifers that occur in the western glaciated plains of North America to model multi-scale heterogeneity and aquifer interconnectivity. Ritzi et al. (2004) have studied the spatial correlation of permeability in cross-stratified sediment with hierarchal architecture using transition probability geostatistics. Weissmann et al. (1999) used 'C-horizon texture data' (i.e., soil obtained at a depth of about $1.5 \mathrm{~m}$ ) that gives some insight for deriving geostatistical correlation structure in the lateral direction, assuming that the morphological processes near the surface are similar to those responsible for formation of the deeper layers. In their approach, the three-dimensional Markov chain model is used in a framework of sequential indicator simulation (SIS) followed by a simulated quenching technique to generate a geostatistical realization. Therefore, their methodology works as follows: (1) calculating the transition probabilities of the chains from field data; (2) transforming the traditional indicator co-Kriging equations of the SIS into a set of equations in terms of transition probabilities; (3) conditioning the model to field data. This conditioning itself involves two steps: (1) establishing an initial configuration by the sequential indicator simulation; and (2) iterative improvement of the initial condition by a simulated quenching algorithm. So this makes the technique inefficient in terms of computer costs. Coupled Markov chain (CMC) seems to have some merits over the above-mentioned approach in the sense that it is conceptually simple, yet theoretically sound. It is efficient in terms of computer time and storage since it does not need to solve Kriging and co-Kriging equations and conditioning is straightforward and inherent in the model; it does not need special treatment by simulated annealing algorithms.

The goals of this study are: (1) application of the CMC model for modeling the heterogeneity of the complex confining layer of an unconsolidated aquifer located in the central Rhine-Meuse delta (the Gorkum study area) in the Netherlands; (2) comparison between the CMC model and the SIS model applied by Bierkens and Weerts (1994) on 


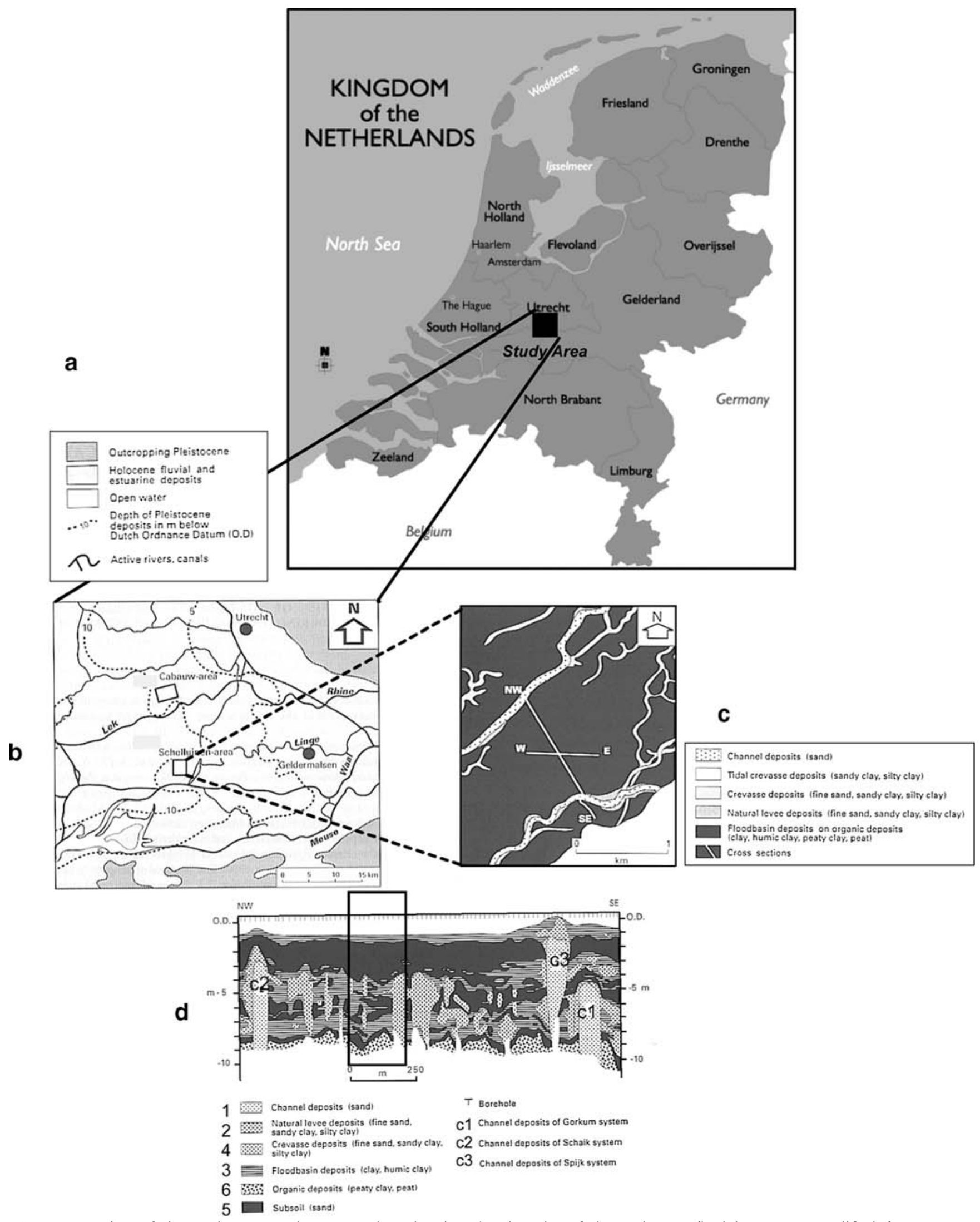

Fig. 1 Location of the study area and cross-section showing the deposits of the Holocene fluvial systems, modified from Weerts (1996). a Shows the Netherlands, b shows the Gorkum area, c delineates the study area and shows the location of the cross-sections NWSE and W-E, d shows the overall cross-section drawn from the boreholes; the window on the image is the part used for the geological simulations (note the vertical exaggeration). Description of lithology codes $1-6$ and channel deposit codes $c 1-c 3$ are also shown 
the same deposit; (3) analysis of the effect of conditioning on a number of boreholes on the reduction of uncertainty of the geological configuration of the confining layer; (4) analysis of the effect of conditioning by displaying uncertainty in probability plots, experimental indicator variograms of each state, overall variograms of the generated realizations, and soil type proportion curves; and (5) analysis of the effect of borehole location on the experimental indicator variogram and soil type proportion curves.

\section{Site description}

The Gorkum study area is located in the central RhineMeuse delta in the Netherlands (Fig. 1). Figure 1d shows the geological cross-section interpreted by geologists based on drillings made $20 \mathrm{~m}$ apart-for details see Bierkens (1994); Bierkens (1996), and Weerts (1996). A brief description is given here. Augured drillings are used to describe the vertical sequence of the confining layers at boreholes. In addition to these drillings, a few measurements of hydraulic conductivity and porosity are performed on sediment cores. Merging soft geological information with a few hard hydraulic data yields estimation for the hydraulic properties of the entire confining layer at the scale of interest. A total of 750 borings are available to a depth of 2-2.5 m below the surface. According to Bierkens (1996), six lithogenetic units are distinguished: channel deposits (sand); natural levee deposits (fine sand, sandy clay, silty clay); crevasse splay deposits (fine sand, sandy clay, silty clay); flood basin deposits (clay, humic clay); peat; and the subsoil, which consists of sandy eolian sediments. In the study area (Fig. 1c), 229 additional drillings were made during 1990 and 1991 . Only 135 boreholes penetrate the entire confining layer. Keshta (2003) has only used the data available in Bierkens (1996) for performing groundwater flow and transport simulations in the confining layer. He did not consider further elaboration on the determination of facies. Coding of the geological materials is displayed in Fig. 1d.

\section{Description of the coupled Markov chain model}

The coupled Markov chain (CMC) model (Elfeki 1996, and Elfeki and Dekking 2001) is applied on the full crosssection (1,650-m cross-section) given in Fig. 1d. As referenced in Elfeki (2006b; with permission from Elsevier), the CMC model is a stochastic model that couples two Markov chains. A chain is used to describe the sequence of lithologies in the vertical direction, and another chain is used in the horizontal direction. The two chains are coupled so that the state in cell $(i, j)$ in the domain depends on the state of two cells, the one on top: $(i, j-1)$, and the other on
Fig. 2 Numbering system in a two-dimensional domain for the coupled Markov chain model: unconditional coupled Markov chain (a), and the coupled Markov chain conditioned on future states (b). Hatched cells are known cells with specific lithology type, while white cells are unknown cells. The future state used to determine the state of cell $(i, j)$ is the state on the same level at cell $\left(N_{\mathrm{x}}, j\right)$ (modified from Elfeki and Dekking 2001)

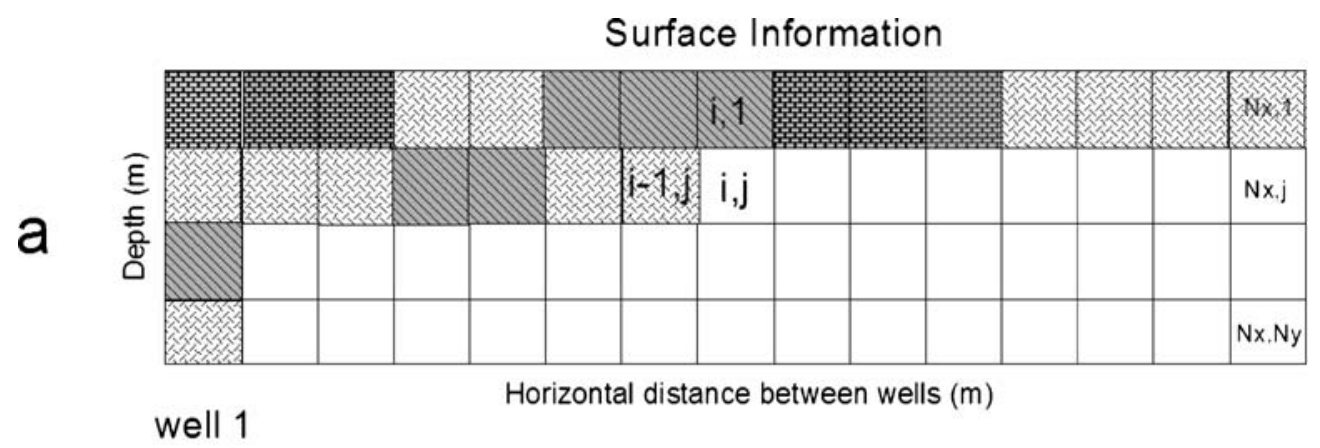

well 1
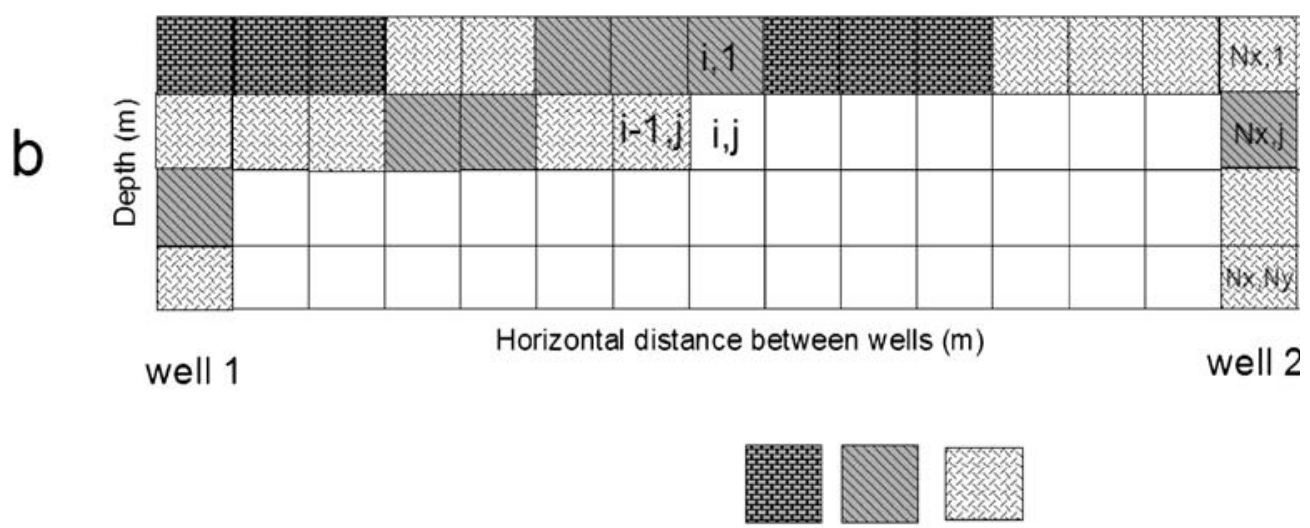

Lithology type

Sand Silt Clay 


\section{Parameter Estimation}

\section{Conditional Simulation}

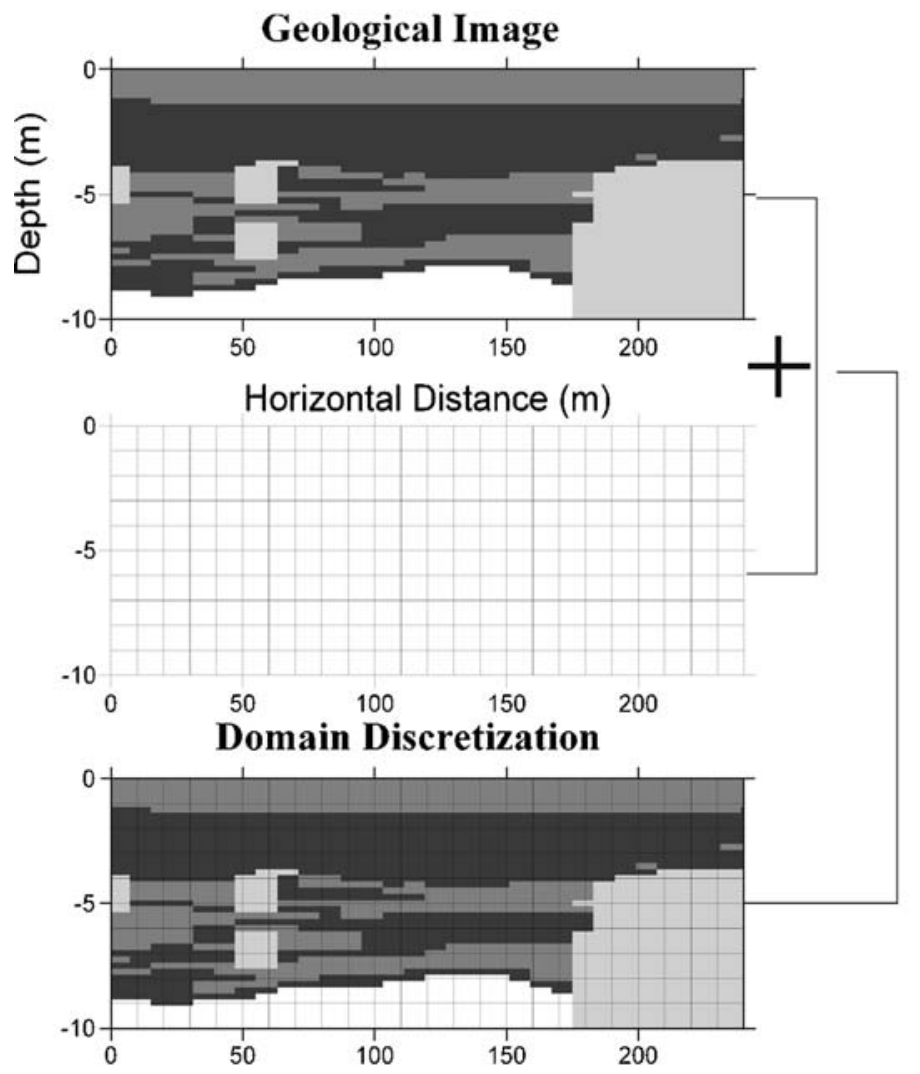

Superposition of the Grid over the Geological Image and Estimation of Transition Probability
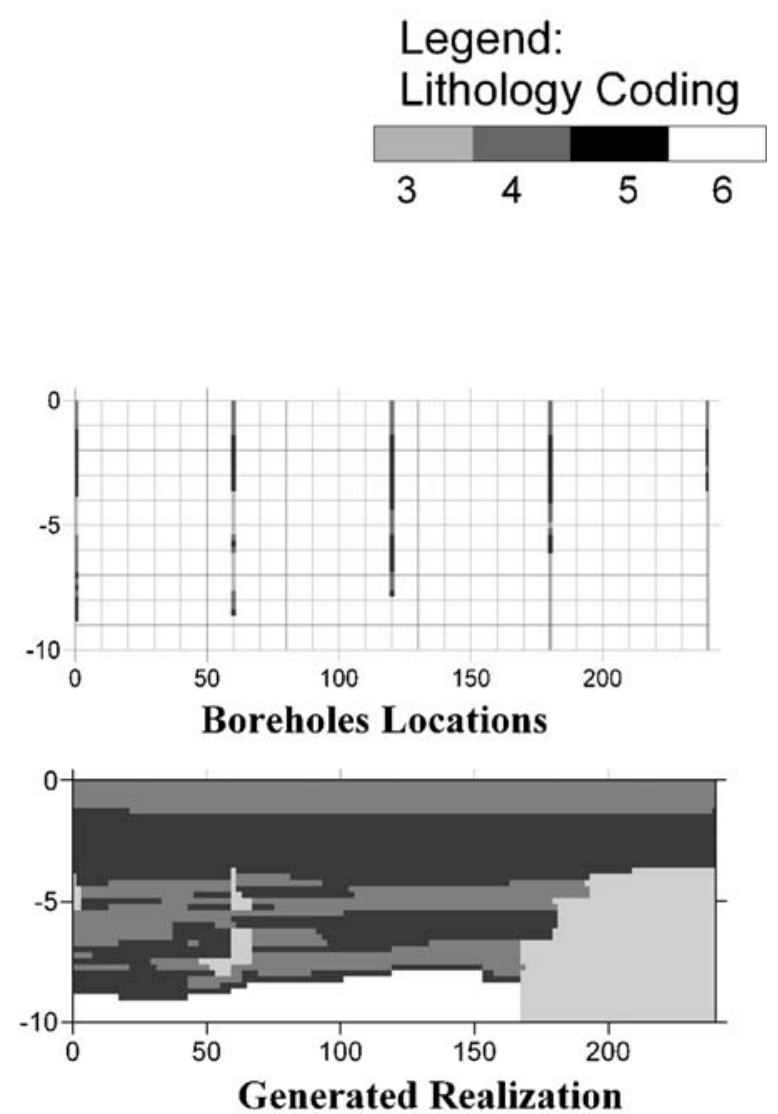

\section{a}

\section{b}

Fig. 3 Estimation of transition probabilities (a) and procedure for conditional simulation on boreholes (b). The section is represented by the window in Fig. 1d

the left: $(i-1, j)$ of the current cell (Fig. 2a). The model could be generalized; it can handle any three cells from various directions. This type of modeling approach is called unilateral Markov random fields (see, e.g., Galbraith and Walley 1976). The reason behind this choice is to develop an efficient generation algorithm of Markovian fields. Traditional Markov random fields (Cross and Jain 1983) use dependence of four neighboring cells that leads to implicit formulation of the generation algorithm. This procedure becomes inefficient in terms of computer time and does not produce satisfactory results from the geological point of view. In field situations, data are usually in the form of boreholes (vertical variability), and surface knowledge (horizontal variability) is gained from a geological survey - see, e.g., the work by Weissmann et al. (1999), which uses 'C-horizon texture data', which in turn, gives some insight for deriving geostatistical correla- tion structure in the lateral direction. The $\mathrm{CMC}$ technique propagates the knowledge available on the left vertical and top horizontal boundaries via the chains into the cells inside the domain. The coupled chain is characterized by transition

Table 1 Horizontal transition probability matrix of the 1,650-m cross-section calculated over sampling intervals of $25 \mathrm{~m}$ (modified from Keshta 2003)

\begin{tabular}{lllllll}
\hline Soil type & 1 & 2 & 3 & 4 & 5 & 6 \\
\hline 1 & 0.979 & 0.004 & 0.001 & 0.006 & 0.009 & 0.001 \\
2 & 0.020 & 0.965 & 0.001 & 0.008 & 0.006 & 0.000 \\
3 & 0.003 & 0.002 & 0.966 & 0.013 & 0.016 & 0.000 \\
4 & 0.000 & 0.001 & 0.009 & 0.983 & 0.007 & 0.000 \\
5 & 0.001 & 0.001 & 0.006 & 0.007 & 0.984 & 0.001 \\
6 & 0.000 & 0.000 & 0.001 & 0.000 & 0.002 & 0.997 \\
\hline
\end{tabular}

Transition probabilities between states 3, 4, 5 and 6 (states on the 240-m section) are shown in italics 
Table 2 Vertical transition probability matrix of the 1,650 - $\mathrm{m}$ crosssection calculated over sampling intervals of $0.25 \mathrm{~m}$ (modified from Keshta 2003)

\begin{tabular}{lllllll}
\hline Soil type & 1 & 2 & 3 & 4 & 5 & 6 \\
\hline 1 & 0.945 & 0.000 & 0.009 & 0.000 & 0.009 & 0.037 \\
2 & 0.071 & 0.796 & 0.021 & 0.041 & 0.071 & 0.000 \\
3 & 0.000 & 0.000 & 0.797 & 0.086 & 0.089 & 0.028 \\
4 & 0.003 & 0.013 & 0.041 & 0.714 & 0.222 & 0.007 \\
5 & 0.004 & 0.012 & 0.047 & 0.119 & 0.768 & 0.050 \\
6 & 0.000 & 0.000 & 0.000 & 0.000 & 0.000 & 1.000 \\
\hline
\end{tabular}

Transition probabilities between states 3, 4, 5 and 6 (states on the $240-\mathrm{m}$ section) are shown in italics

probabilities from the two chains by an application of Bayes' rule,

$$
\begin{aligned}
p_{l m, k}: & =\operatorname{Pr}\left(Z_{i, j}=S_{k} \mid Z_{i-1, j}=S_{l}, Z_{i, j-1}=S_{m}\right) \\
& =\frac{p_{l k}^{h} \cdot p_{m k}^{v}}{\sum_{f} p_{l f}^{h} \cdot p_{m f}^{v}} . \quad k=1, \ldots n
\end{aligned}
$$

where $p_{\mathrm{lm}, \mathrm{k}}$ is the probability that cell $(i, j)$ is in state $S_{\mathrm{k}}$ given that cell $(i-1, j)$ is in state $S_{1}$ and cell $(i, j-1)$ is in state $\mathrm{S}_{m}, Z_{i, j}$ is the state of cell $(i, j), Z_{i-1, j}$ is the state of cell $(i-1, j), Z_{i, j-1}$ is the state of cell $(i-1, j), p_{l k}^{h}$ and $p_{m k}^{v}$ are the corresponding elements of the horizontal (superscript $h$ ) and vertical transition probability (superscript v) matrices and $n$ is the number of states in the geological deposit.

Elfeki and Dekking (2001) have extended the CMC model to conditioning on any number of boreholes. The methodology is based on the concept of conditioning the horizontal Markov chain on future states (Fig. 2b). The conditioning is explicit in nature where iteration is not needed to reach convergence around the conditioning data, as other methods do (e.g., Cross and Jain 1983). This makes the methodology efficient in terms of computer time and storage. The conditioning formula is given by,

$$
\begin{aligned}
p_{l m, k \mid q}: & =\operatorname{Pr}\left(Z_{i, j}=S_{k} \mid Z_{i-1, j}=S_{l}, Z_{i, j-1}=S_{m}, Z_{N_{x}, j}=S_{q}\right) \\
& =\frac{p_{l k}^{h} \cdot p_{k q}^{h\left(N_{x}-i\right)} \cdot p_{m k}^{v}}{\sum_{f} p_{l f}^{h} \cdot p_{f q}^{h\left(N_{x}-i\right)} \cdot p_{m f}^{v}}, \quad k=1, \ldots, n .
\end{aligned}
$$

where is the probability that cell $(i, j)$ is in state $S_{\mathrm{k}}$ given that cell $(i-1, j)$ is in state $S_{1}$ and cell $(i, j-1)$ is in state $S_{\mathrm{m}}$ and cell $\left(N_{\mathrm{x}}, j\right)$ is in state $S_{\mathrm{q}}$, and $p_{k q}^{h\left(N_{x}-i\right)}$ is the probability to go from $S_{\mathrm{k}}$ to $S_{\mathrm{q}}$ in $\left(N_{\mathrm{x}}-i\right)$-steps.

\section{Inference of Markov chains parameters}

The transition probabilities are derived from the data in the $1,650-\mathrm{m}$ cross-section (the methodology is described in Fig. 3 on the $240-\mathrm{m}$ cross-section). Although data could be limited only to the boreholes where observations can be made, it is assumed that the $1,650-\mathrm{m}$ crosssection is still highly reliable in this modeling exercise because the cross-section is drawn from a dense network of drillings (750 borings) in the experimental site (Bierkens 1994).

Estimation of sampling intervals. As a general rule, the proper sampling interval in the vertical direction must be less than or equal to the minimum thickness of the geological unit observed in the borehole (Lin and Harbaugh 1984). For the horizontal direction, the proper sampling interval must be less than or equal to the minimum length of the geological unit found in the domain. It was found that sampling intervals of $\Delta x=25 \mathrm{~m}$ for the $1,650-\mathrm{m}$ cross-section, $\Delta x=2 \mathrm{~m}$ for the $240 \mathrm{~m}$ part of the $1,650-\mathrm{m}$ cross-section and $\Delta z=0.25 \mathrm{~m}$ for both sections are appropriate values.

Estimation of transition probabilities. First, the tally matrix of transitions is obtained by superimposing a grid with equidistant points (the sampling intervals) in both vertical and horizontal directions over the geological map (see Fig. 3a). The transition frequencies, e.g., in the vertical direction, are calculated between the states by counting how many times a given state $S_{1}$ is followed by itself or by another state $S_{\mathrm{k}}$ in the vertical direction, and then it is divided by the total number of transitions in the vertical direction (Davis 1986),

$p_{l k}^{v}=\frac{T_{l k}^{v}}{\sum_{q=1}^{n} T_{l q}^{v}}$

\begin{tabular}{|c|c|c|c|c|c|c|c|c|c|}
\hline \multicolumn{5}{|c|}{ Length of the given section $(240 \mathrm{~m})$} & \multicolumn{5}{|c|}{ Depth of the given section $(10 \mathrm{~m})$} \\
\hline \multicolumn{5}{|c|}{ Sampling interval in x-direction $(2 \mathrm{~m})$} & \multicolumn{5}{|c|}{ Sampling interval in y-direction $(0.25 \mathrm{~m})$} \\
\hline \multicolumn{10}{|c|}{ No. of states (4) } \\
\hline \multicolumn{5}{|c|}{ Horizontal transition probability matrix } & \multicolumn{5}{|c|}{ Vertical transition probability matrix } \\
\hline State & 3 & 4 & 5 & 6 & State & 3 & 4 & 5 & 6 \\
\hline 3 & 0.979 & 0.010 & 0.011 & 0.000 & 3 & 0.969 & 0.027 & 0.004 & $\overline{0.000}$ \\
\hline 4 & 0.011 & 0.974 & 0.015 & 0.000 & 4 & 0.008 & 0.724 & 0.268 & 0.000 \\
\hline 5 & 0.008 & 0.012 & 0.977 & 0.003 & 5 & 0.025 & 0.139 & 0.791 & 0.045 \\
\hline 6 & 0.010 & 0.000 & 0.007 & 0.983 & 6 & 0.000 & 0.000 & 0.000 & 1.000 \\
\hline
\end{tabular}

Table 3 Horizontal and vertical transition probability matrices of the 240-m cross-section modified from Keshta (2003) and reprinted from Elfeki 2006b with permission from Elsevier 
where $p_{l k}^{v}$ denotes the probability of transition from state $S_{1}$ to $S_{\mathrm{k}}$ in the vertical direction, $T_{l k}^{v}$ is the number of observed transitions from $S_{1}$ to $S_{\mathrm{k}}$ in the vertical direction.

A similar procedure is performed to compute the horizontal transition probability matrix. Tables 1 and 2 show the transition probabilities estimated from the data for the overall cross-section displayed in Fig. 1d, while Table 3 shows the transition probability matrices in the horizontal and the vertical directions for the $240 \mathrm{-m}$ part of the overall section. The transition probabilities of states 3 ,
4, 5 and 6 in the 1,650-m cross-section and on the $240-\mathrm{m}$ cross-section look similar. This suggests that the $240-\mathrm{m}$ section is globally representative of the $1,650-\mathrm{m}$ crosssection. However, $p_{3 i}$ where $i=1,2,3$ and 4 in the vertical direction looks different in Tables 2 and 3 . The reason is that when the $1,650 \mathrm{~m}$ cross-section is considered, state 3 is treated in a way that there is a possible transition to state 6 (the bottom layer). However, in the 240 -m cross-section, state 3 is extended further down to the bottom leading to no transitions to state 6 and consequently the other
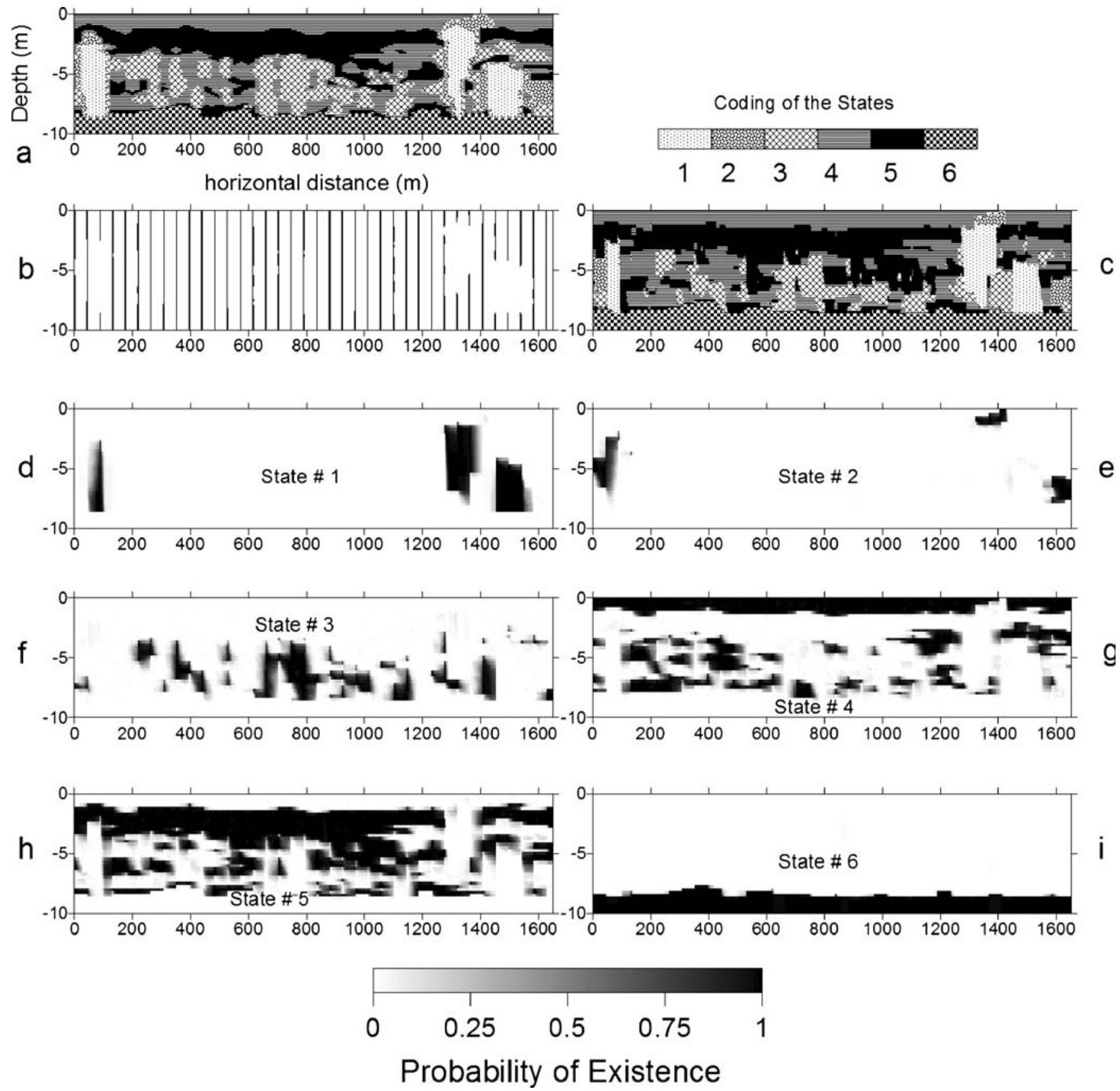

Fig. 4 Application of the CMC on the 1,650-m cross-section conditioned on 39 boreholes. a The schematized picture of the overall crosssection. b Shows the boreholes location and lithologies observed at each borehole. The corresponding stochastic simulation (single realization) conditioned on these boreholes is shown in (c). d-i Images are ensemble indicator functions of the six lithologies/states (i.e., probability of existence of each lithology) 

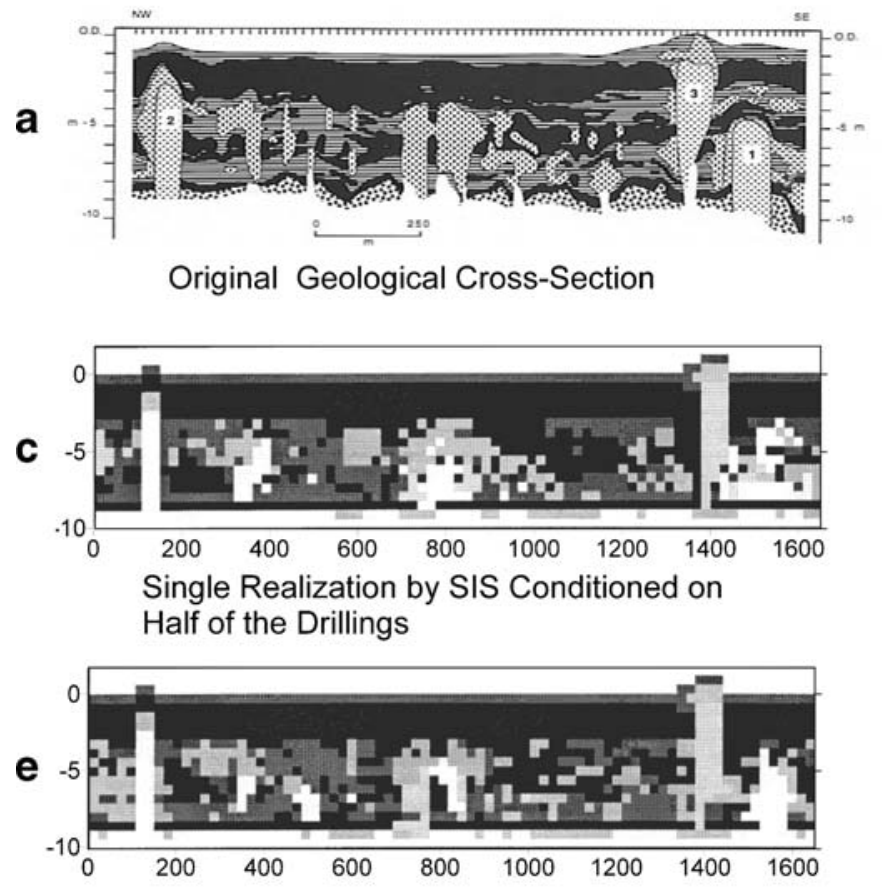

Single Realization by SIS Conditioned on All Drillings
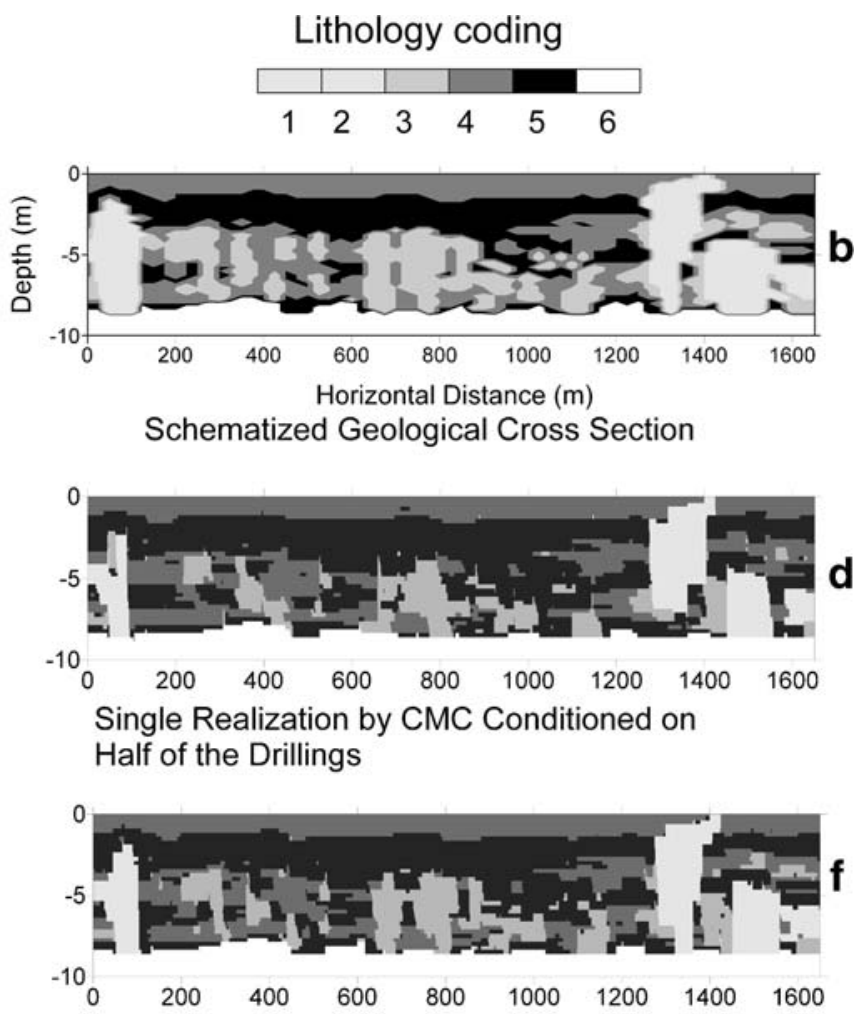

Single Realization by CMC Conditioned on All Drillings

Fig. 5 Comparison between SIS and CMC models on the 1,650-m cross-section. a Reproduction of the original geological section shown in Fig. 1d, for comparison purposes. b Schematized image of the confining layers. c Shows a single realization by SIS and $\mathbf{d}$ shows a single realization by CMC (note that the whole space is simulated; nothing is treated deterministically except the boreholes), both conditioned on half of the drillings (39 boreholes). e-f Show a similar comparison conditioned on all drillings ( 81 boreholes)

transitions have to change accordingly. This gives an idea about the sensitivity of the estimation procedure for the model parameters.

\section{Disussion of geostatistical results}

\section{The overall 1,650-m cross-section}

The CMC model is used to generate realizations of the 1,650-m cross-section shown in Fig. 1d. The statistical parameters (i.e., transition probabilities) given in Table 1 are estimated from the schematic picture displayed in Fig. 1. This picture, as any model is a simplification of reality, will be considered as a training image. Actually, because the picture is constructed from a dense network of drillings ( 750 borings in the cross-section, and also drillings in its neighborhood) there is reasonable confidence in the geological structure made by the geologists. The simulation of the cross-section has been conditioned on 39 boreholes, shown in Fig. 4b. A single generated realization is presented in Fig. 4c, which shows good agreement in terms of reproducing the geological features (connectivity, disconnectivity and configurations of the units).

In order to evaluate the uncertainty and the degree of variability between the realizations, a Monte Carlo approach is followed. One hundred realizations are generated and the ensemble average is calculated for the indicator function of each state (geological unit or lithology). The indicator function of state $S_{\mathrm{k}}$ is given by,

$I_{k}(\mathbf{x})= \begin{cases}1 & \text { if } S_{k} \text { is located at position } \mathbf{x} \\ 0 & \text { if } S_{k} \text { is not located at position } \mathbf{x} .\end{cases}$

The ensemble average, calculated using 100 realizations of the indicator function, can be considered as a measure of the probability of occurrence $\pi^{\mathrm{k}}(\mathbf{x})$ of a specific lithology $S_{k}$ located at specific point $\mathbf{x}$ in space (where $\mathbf{x}$ is the position vector in two-dimensions). This probability is given by

$\pi^{k}(x)=\frac{1}{M C} \sum_{R=1}^{M C} I_{k}^{(R)}(\mathbf{x})$.

where MC is the number of Monte Carlo runs and $R$ is the indicator for a realization number.

When the ensemble average of the indicator function equals 1 , it means that there is $100 \%$ certainty that the lithology $S_{\mathrm{k}}$ is located at $\mathbf{x}$, and when the indicator function 
Legend:

Lithology Coding

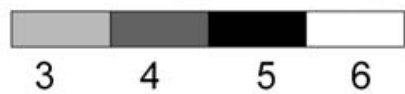

\section{Boreholes}

\section{Boreholes}

\section{Boreholes}

\section{Boreholes}

\section{Boreholes}

\section{Boreholes}
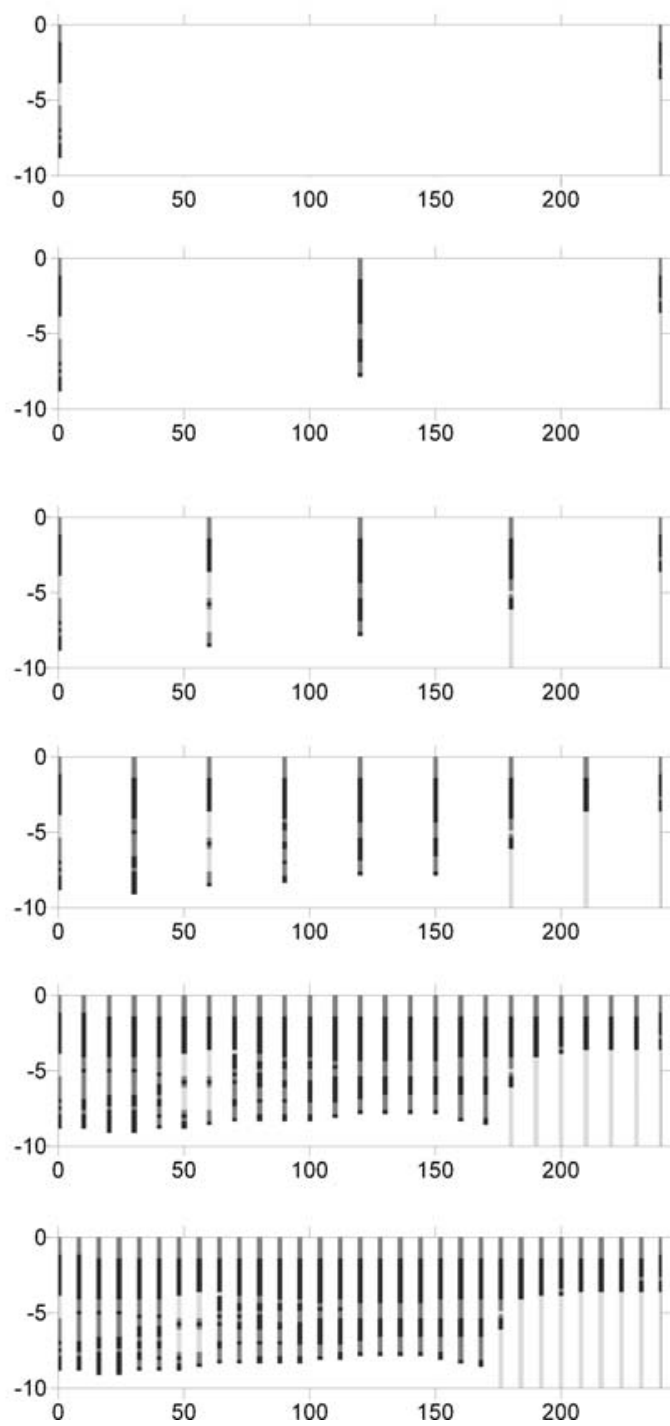

Original Section
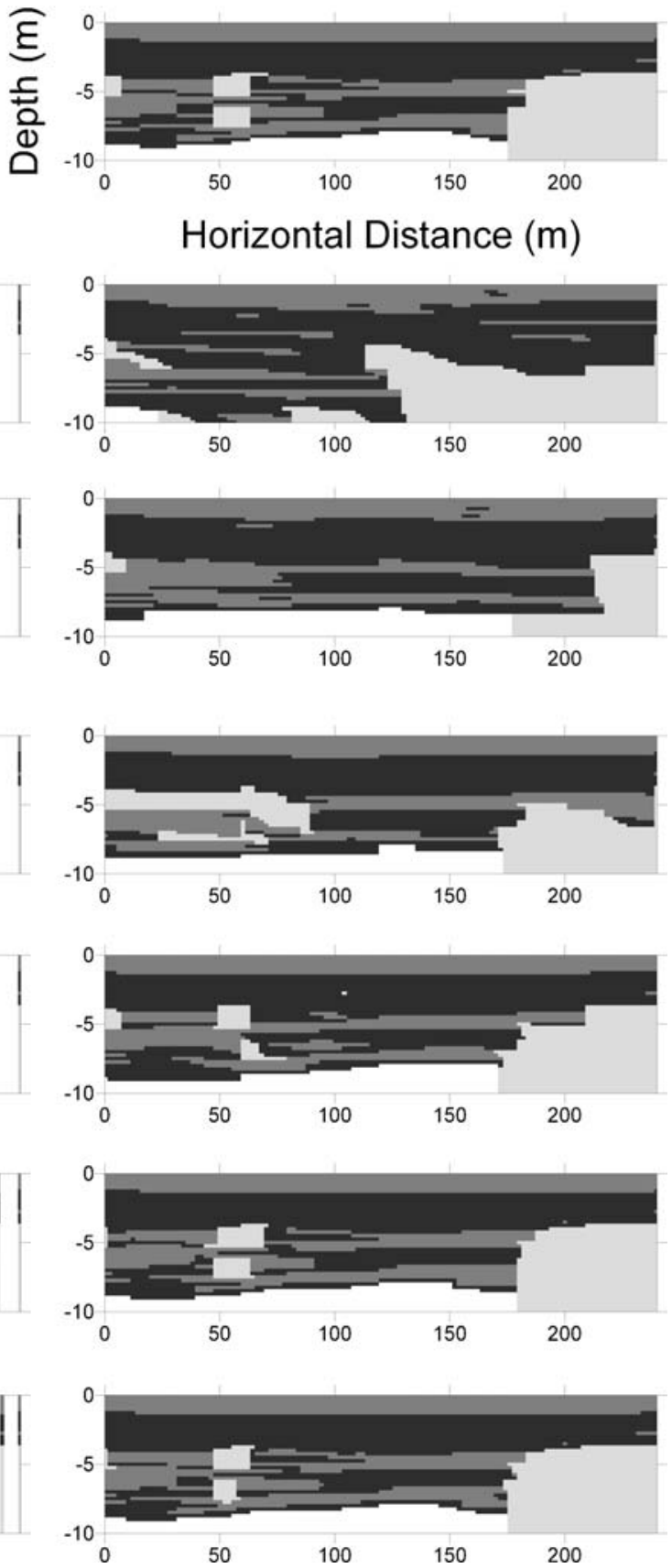

Fig. 6 Performance of conditioning. Top right shows the original 240-m cross-section and below this are shown the results of conditioning with increasing number of boreholes in a single realization $(2,3,5,9,25$ and 31 boreholes are used respectively). The left panel shows borehole locations and lithologies observed at each borehole. The right panel shows corresponding stochastic simulations of the geological structures (single realizations); explanation of the lithology coding is given with Fig. 1d

is zero, it means there is $100 \%$ certainty that the lithology $S_{\mathrm{k}}$ is not located at $\mathbf{x}$. Figure $4 \mathrm{~d}-\mathrm{h}$ shows images of the ensemble average of the indicator functions of the six lithologies conditioned on 39 boreholes. It is clear from the indicator maps that there are no large fluctuations over the realizations, which means that the same pattern is almost preserved over all realizations. There are, of course, some slight variations at the boundaries of each lithology which appear clearly in dark gray, and turn to white gradually.

Figure 5 displays a comparison between SIS (GomezHernandez and Srivastava 1990) and CMC methods on the overall/1650 m cross-section. The SIS method was applied by Bierkens and Weerts (1994) and the results of single realizations conditioned on half of the drillings and 
Fig. 7 Performance of indicator variograms of single realizations of the $240 \times 10 \mathrm{~m}$ cross-section shown in Fig. 6 in the $\mathrm{x}$ - (left panel) and the z-direction (right panel), with conditioning on $2,3,5,9$ and 25 boreholes
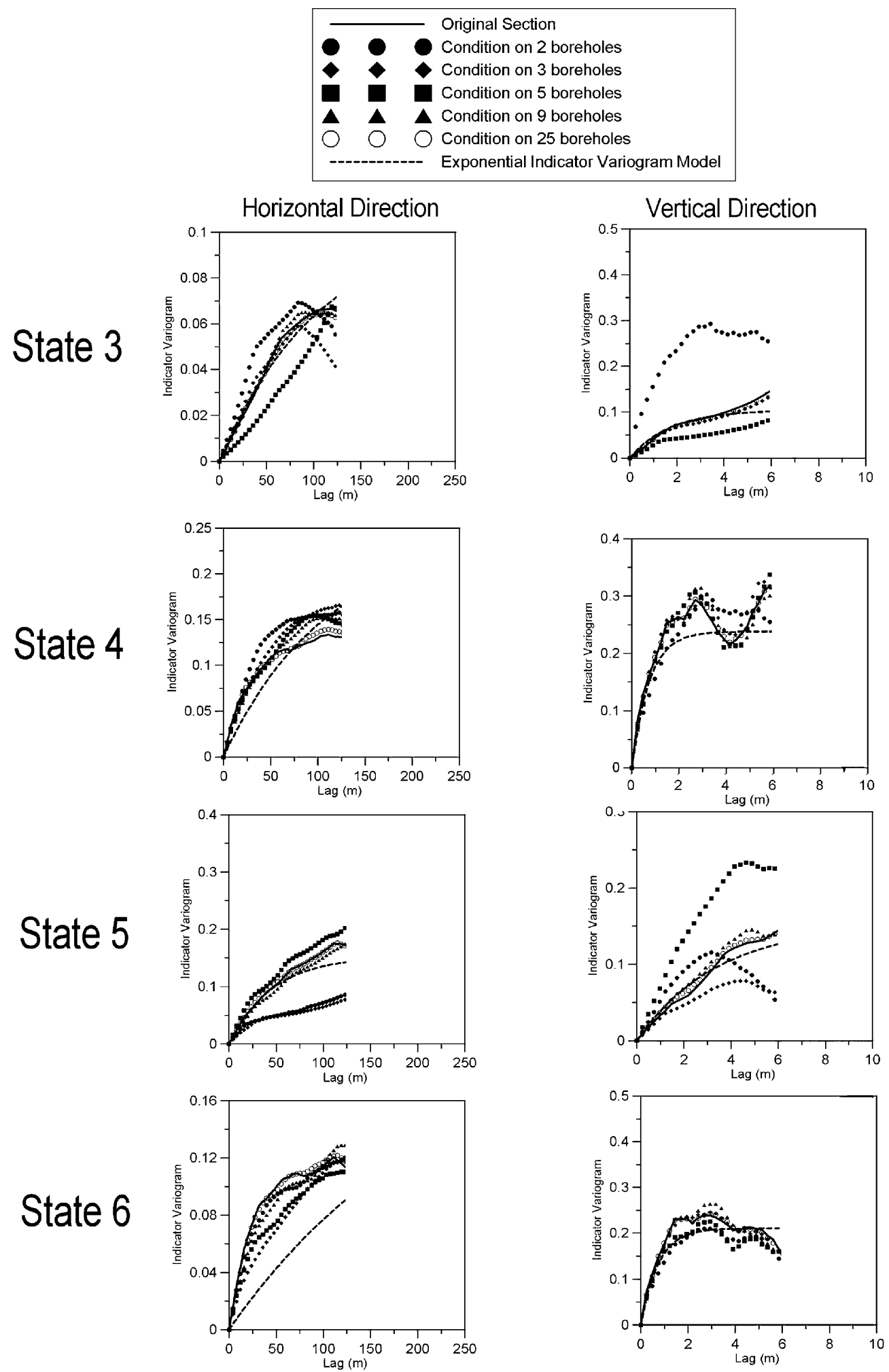

all the drillings are shown in Fig. 5c and e, respectively. The corresponding single realizations by the CMC method are shown in Fig. 5d and f, respectively. It is important to mention that when the SIS method is applied, large parts of the cross-section (the top layers of the cross-section where lithologies 3 and 5 are located (see Fig. 1d) and the channel deposits numbered c1, c2, and c3 in Fig. 1d) are treated deterministically (i.e., some facies are simply inserted as known objects in their locations before performing the SIS simulations). The rest of the image is 
Table 4 Soil properties at core scale of the $240 \times 10 \mathrm{~m}$ crosssection from Bierkens 1996)

\begin{tabular}{lllll}
\hline Code $(i)$ & Soil type & $W_{i}$ & $\left\langle Y_{i}\right\rangle$ & $\sigma_{Y_{i}}^{2}$ \\
\hline 3 & Sand and silty clay & 0.19 & -4.97 & 3.49 \\
4 & Clay and humic clay & 0.30 & -7.00 & 2.49 \\
5 & Peat & 0.39 & -2.00 & 1.7 \\
6 & Fine and loamy sand & 0.12 & 0.60 & 1.76
\end{tabular}

$W_{i},\left\langle Y_{i}>, \sigma_{Y_{i}}^{2}\right.$ are the proportion in the cross-section, mean and variance of the logarithm of conductivity of lithology $(i)$ respectively

generated by the SIS method and conditioned on the boreholes. In the simulation by the CMC method, nothing is treated deterministically except the conditioning boreholes.

Both methods reproduce more or less the same geological features in the cross-section. However, some of the advantages of the CMC model over the SIS model should be emphasized:

1. CMC uses the direct data (single-step transition probabilities from the geological image interpreted by the geologists from Tables 1 and 2) without performing any modeling of these transitions, which preserves the spatial structure displayed in Fig. 1d (which is assumed to be the "truth"). The formula Eq. (2) takes care of the n-step transition probabilities. In the SIS model, however, the spatial structure of the data is modeled by fitting variograms (in this study, Bierkens 1994 used a spherical model with nugget effect), which often loose the real spatial structure, and estimation of variograms is not reliable at large lags because of lack of data.

2. The CMC model is able to capture the geological features fairly correctly without treating some parts of the image as known objects in the contrary of SIS model application.

3. The simulations performed using SIS required making a distinction between three sub-layers of the non-distinct

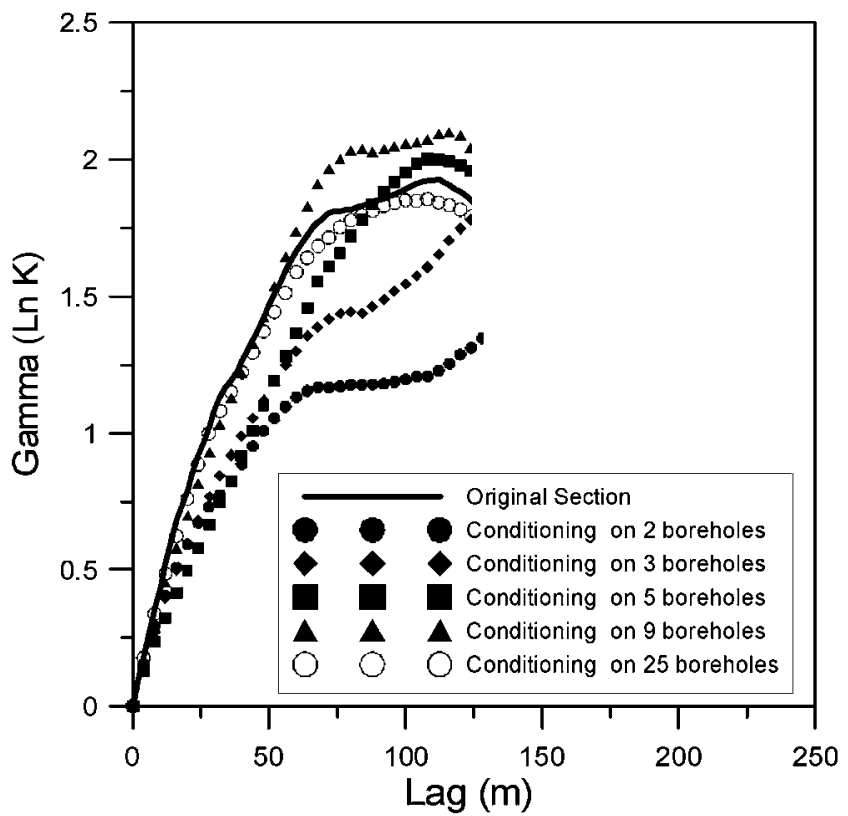

lithogenetic units (upper sub-layer $4.5 \mathrm{~m}$ thickness, middle sub-layer $0.5 \mathrm{~m}$ thickness and lower sub-layer $0.5 \mathrm{~m}$ thickness). For each of these sub-layers, variogram parameters were estimated. However, in the CMC model all the statistical parameters of the lithogenetic units are captured in the two transition-probability matrices (namely, the horizontal and vertical ones in Tables 1 and 2).

\section{Part of the cross-section $(240 \times 10 \mathrm{~m})$}

Single realization analysis. Figure 6 shows the performance of conditioning of the geological structure on the number of boreholes. It is obvious that increasing the number of boreholes leads to improved characterization of the geological configuration. Nine boreholes with spacing $30 \mathrm{~m}$ are the least number of boreholes that capture the global features of the geological structure (i.e., the delineation of the facies). It is obvious that conditioning controls the lengths of the facies. In Fig. 6, the rows representing two and three boreholes show this effect. By introducing the middle borehole (of the three), the length of the sand channel (lithology no. 6) at the bottom of the cross-section was increased, while the size of the channel on the bottom right (lithology no. 3) was reduced.

Effect of the number of boreholes on indicator variograms. A metric measure of the spatial correlation by determining the indicator variogram is shown in Fig. 7. The indicator variogram is computed by,

$\gamma_{k k}(\mathbf{s})=\frac{1}{2 n(\mathbf{s})} \sum_{i=1}^{n(\mathbf{s})}\left[I_{k}\left(\mathbf{x}_{i}\right)-I_{k}\left(\mathbf{x}_{i}+\mathbf{s}\right)\right]^{2}$

where $n(\mathbf{s})$ is the number of pairs that have a separation vector $\mathbf{s}$.

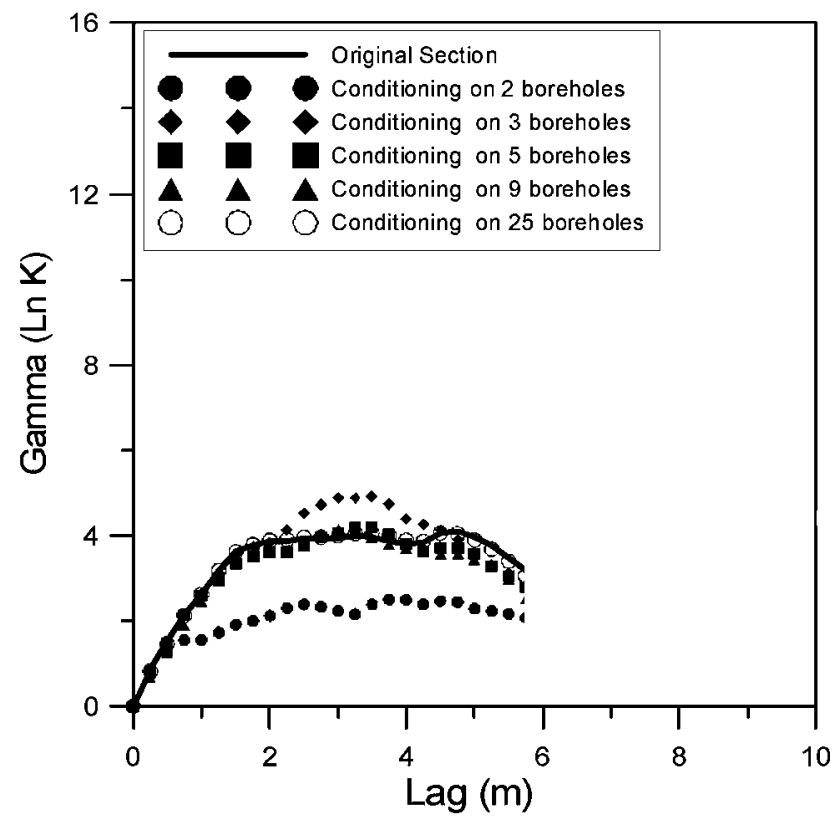

Fig. 8 Performance of global variograms of single realizations of the $240 \times 10 \mathrm{~m}$ cross-section shown in Fig. 6 in the $\mathrm{x}$ - (left panel) and the y-direction (right panel), with conditioning on 2, 3, 5, 9 and 25 boreholes 


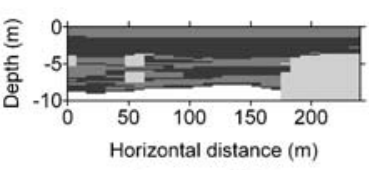

State \# 6
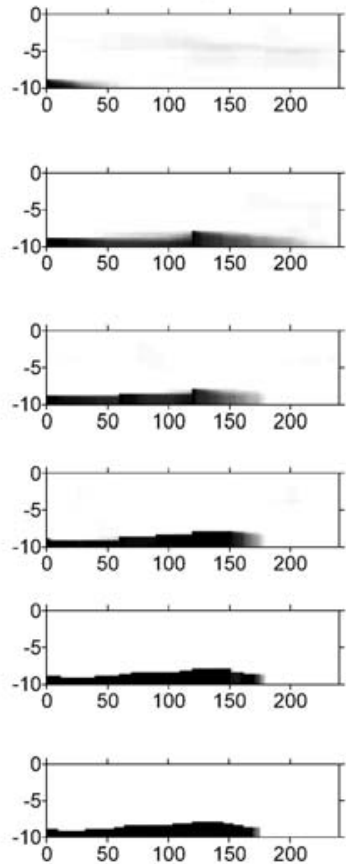

Legend:

Lithology Coding

\begin{tabular}{llll}
\hline & 4 & 5 & 6
\end{tabular}

State \# 5
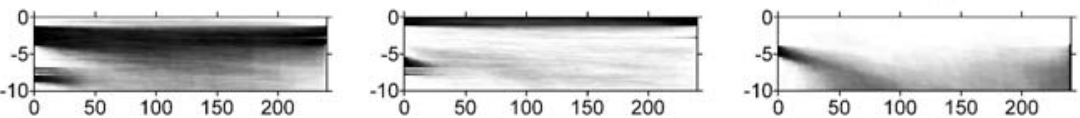

2 Boreholes
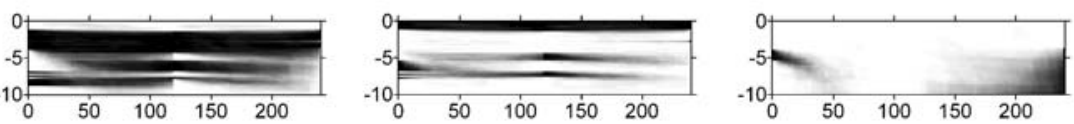

3 Boreholes
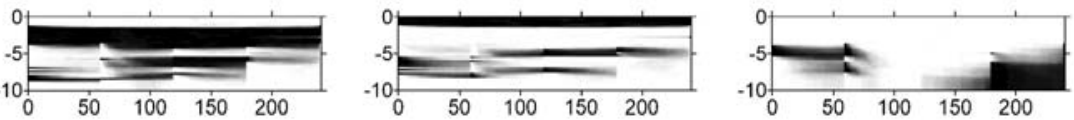

5 Boreholes
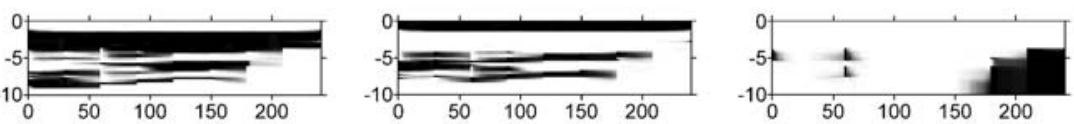

9 Boreholes
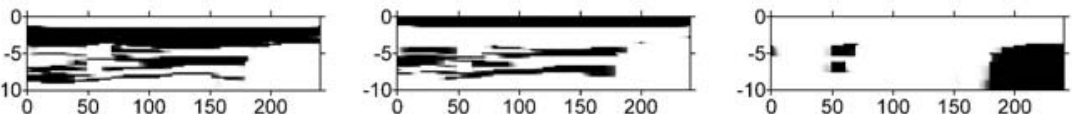

25 Boreholes
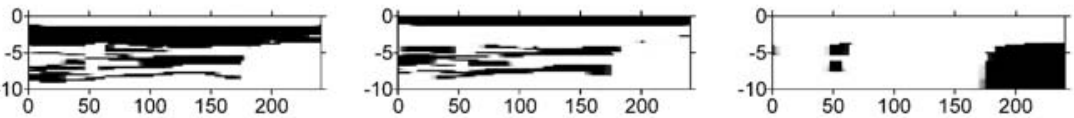

31 Boreholes

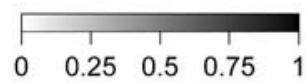

\section{Probability of occurance}

Fig. 9 Performance of conditioning. Top left shows the original 240-m cross-section and below this are shown the effect of increasing number of boreholes on the uncertainty of each lithology $(2,3,5,9,25$ and 31 boreholes respectively). Bottom scale bar is the probability of occurrence

Fig. 10 Convergence of state proportions by conditioning on number of boreholes

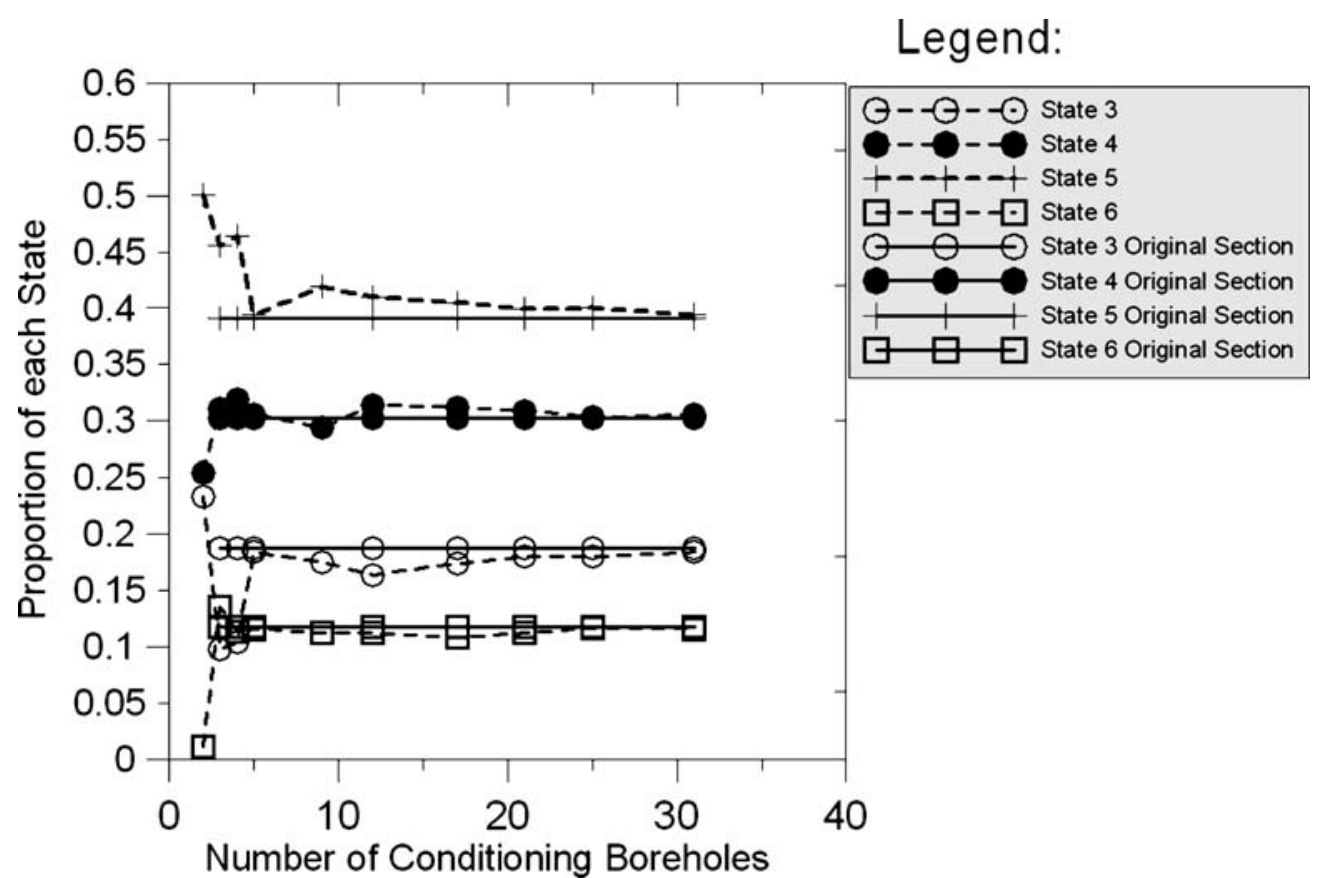


Fig. 11 Performance of the location of the conditioning middle borehole in a single realization. Top image shows the original cross-section and below this are shown performance for borehole location at $30,60,90,120,150,180$ and $210 \mathrm{~m}$, respectively
Original Section

Middle Borehole at $30 \mathrm{~m}$

Middle Borehole at $60 \mathrm{~m}$

Middle Borehole at $90 \mathrm{~m}$

Middle Borehole at $120 \mathrm{~m}$

Middle Borehole at $150 \mathrm{~m}$

Middle Borehole at $180 \mathrm{~m}$

Middle Borehole at $210 \mathrm{~m}$
Legend:

Lithology Coding
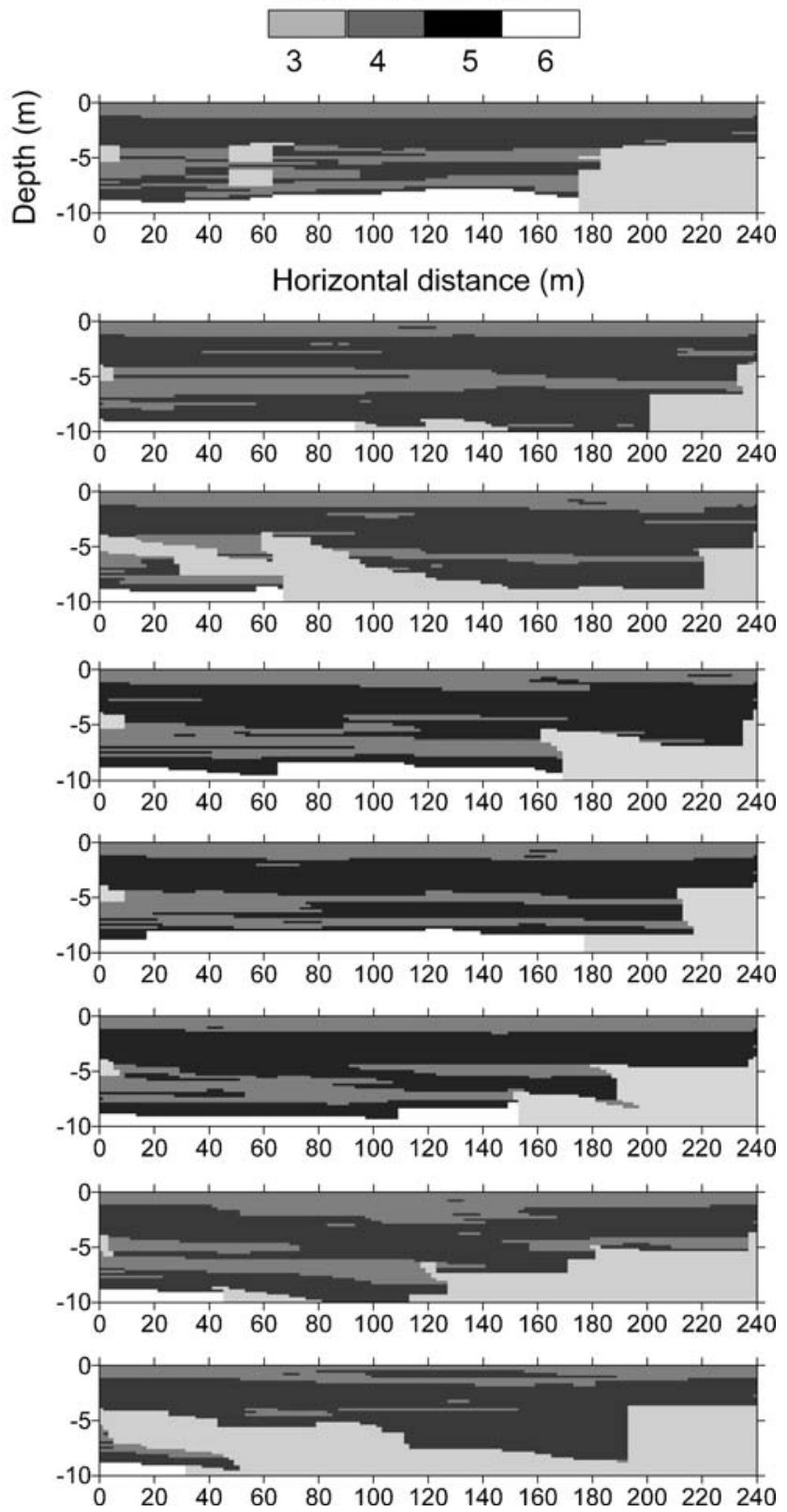

The variogram is computed in both the $\mathrm{x}$ - (left panel in Fig. 7) and z- (right panel in Fig. 7) directions. The graph emphasizes the fact that nine boreholes are the least number of boreholes to reproduce the variogram of the original section. A stationary exponential variogram model is given by,

$\gamma_{k k}(\mathbf{s})=w_{k}\left(1-w_{k}\right)\left[1-e^{-\frac{|\mathbf{s}|}{\lambda_{k}}}\right]$

where, $w_{\mathrm{k}}$ is the proportion of state $S_{\mathrm{k}}, \mathbf{s}$ is the vector of the separation distance, and $\lambda_{\mathrm{k}}$ is the fitted correlation length, which is plotted in the Fig. 7 for comparison purposes. The fitting is performed by computing the correlation length from the indicator variogram of the original section adopting the following condition (similar to Gelhar 1993 for the autocorrelation function):

$$
\lambda_{k}=s \text { at } \gamma_{k k}(\mathbf{s}) \geq w_{k}\left(1-w_{k}\right)\left[1-\frac{1}{e}\right]
$$

The exponential variogram is also plotted in Fig. 7 to illustrate the deviation from stationarity. It is obvious that many variograms do not show stationary behavior. 
Fig. 12 Performance of indicator variograms of single realizations of the $240 \times 10 \mathrm{~m}$ cross-section shown in Fig. 11 in the $\mathrm{x}$ - (left panel) and the z-direction (right panel), with middle borehole conditioning at $30,60,90,120,150,180$ and $210 \mathrm{~m}$ respectively

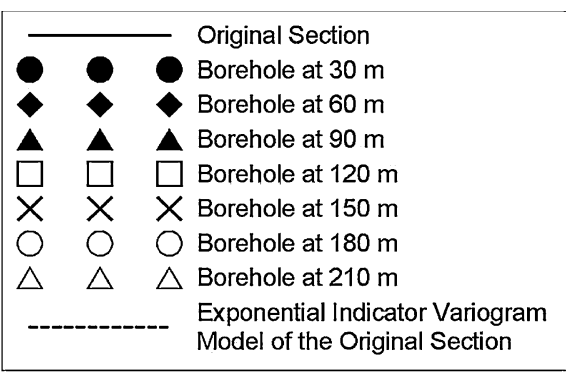

Horizontal Direction
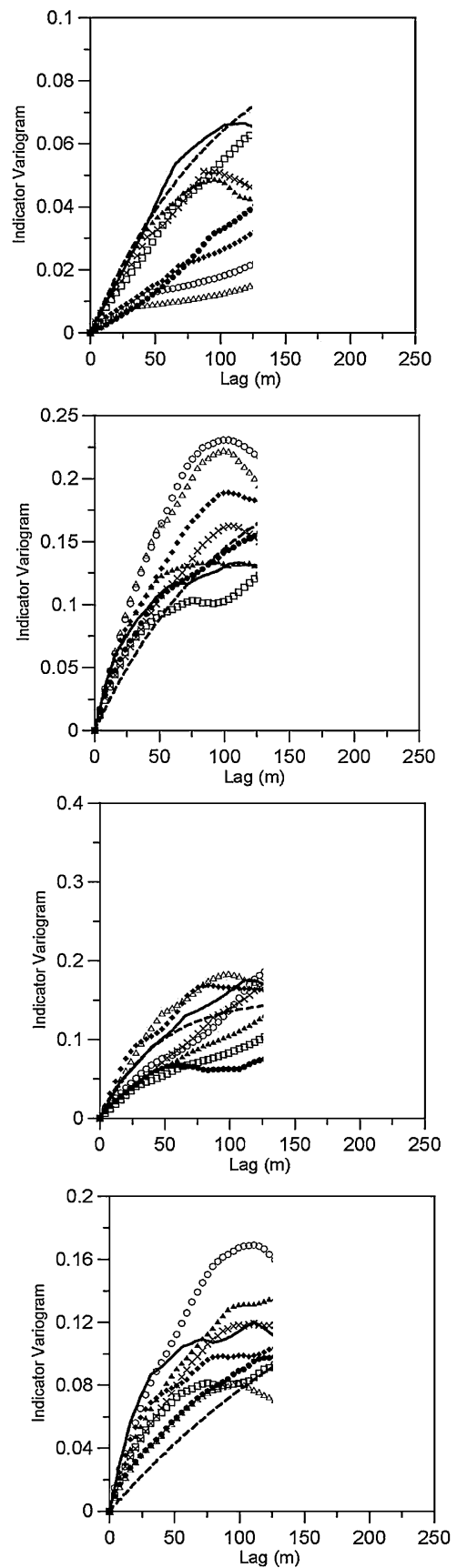

Vertical Direction
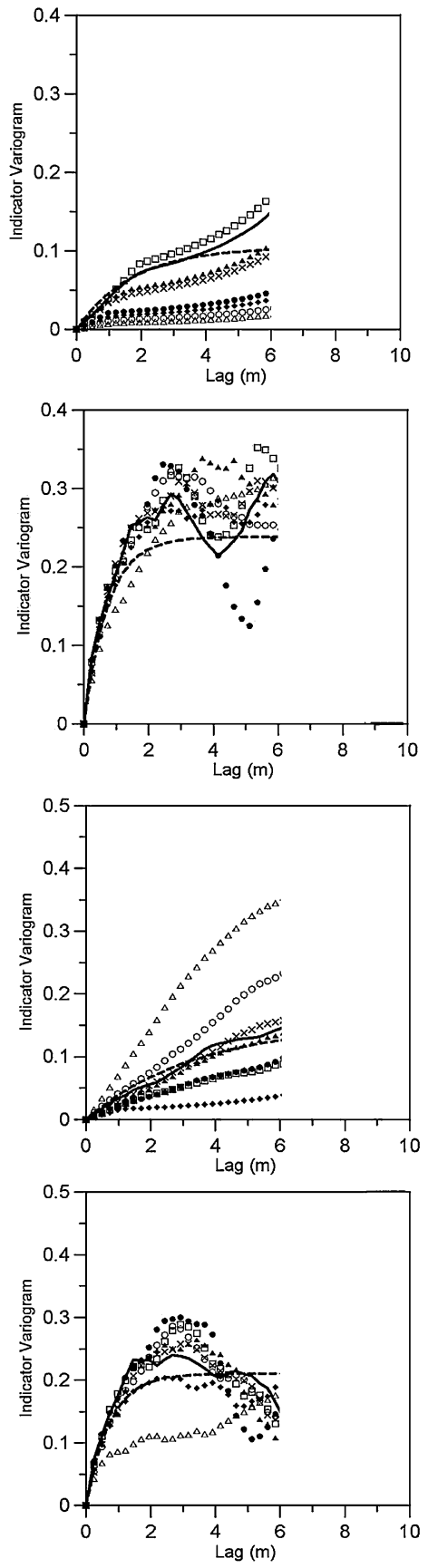
Effect of the number of boreholes on the global variogram. A global parameter variogram analysis is performed on the same part of the cross-section $(240 \times 10 \mathrm{~m})$ to study the influence of conditioning on the number of boreholes on the shape of the global variogram of $Y(\mathbf{x})=\ln (K(\mathbf{x}))$, where $K(\mathbf{x})$ is the hydraulic conductivity of each unit, in both the $\mathrm{x}$ - and z-directions (values of $Y(\mathbf{x})$ are shown in Table 4). The conditioning scenarios considered in this study are 2 , $3,5,9,12,17,25$, and 31 boreholes with spacing 240,120 , $60,30,20,15,10$, and $8 \mathrm{~m}$ respectively. The variogram $\gamma(\mathbf{s})$ of $Y(\mathbf{x})$ is estimated by

$\gamma(\mathbf{s})=\frac{1}{2 n(\mathbf{s})} \sum_{i=1}^{n(\mathbf{s})}\left[Y\left(\mathbf{x}_{i}\right)-Y\left(\mathbf{x}_{i}+\mathbf{s}\right)\right]^{2}$,

where $n(\mathbf{s})$ is the number of pairs that has a separation vector $\mathbf{s}$. Figure 8 shows the performance of the variogram reproduction of single realizations (the realizations of the geological patterns are displayed in Fig. 6). Figure 8 shows how the variogram of each conditioning scenario converges to the real variogram when the number of boreholes is increased. One may observe that in the vertical direction five boreholes were the minimum number to capture the vertical variability. The variogram shows stationary behavior in the vertical direction. The indicator variogram in the vertical direction (Fig. 7 right panel) shows that the dominant state that influences the global variogram (Fig. 8 left panel) is state 6 .

However, in the $\mathrm{x}$-direction, convergence is reached by conditioning on 25 boreholes. This is due to the high complexity of the geological structures of these layers. An important feature in Fig. 8 is that, although the variogram shape of the section in the horizontal direction shows more or less stationary behavior (i.e., reaches a sill at about 1.75), the geological features do not show a stationary pattern. This leads to the conclusion that variogram shapes can be deceptive and do not reflect the real spatial structure of the field. The variogram (in Fig. 8) shows different sill values in both directions (if one considers that it reaches a sill in the z-direction). This emphasizes the non-stationarity in the field. It seems that all states present in the global variogram shape in both the horizontal and vertical directions, if one inspects the indicator variogram in the horizontal direction (Fig. 7 left panel) and global variogram in Fig. 8 (left panel). For more details about de-convolution of the variogram, a reference is made to Proce et al. (2004).

Multi-realizations. Figure 9 shows the effect of conditioning on the uncertainty (described in terms of probability of occurrence) of each lithology. As might be expected, the probability of occurrence will tend towards one of the extreme values 0 or 1 . The results of the probability maps seem to stabilize when conditioning is carried out over 25 boreholes (spacing $10 \mathrm{~m}$ ). However, nine boreholes (spacing $30 \mathrm{~m}$ ) seem to be reasonable in practice.

Convergence of proportions of the states as a function of the number of boreholes. Figure 10 shows a second metric measure which is the proportion of each state. The proportions are calculated at each conditioning scenario and compared with the original section. The curve shows convergence by increasing the number of boreholes. The convergence is of oscillatory type at less than 17 boreholes (15-m spacing). This is due the fact that in some conditioning scenarios; layers can get connected, leading to an increase in the proportion of the state; in other
Fig. 13 Convergence of state proportions by conditioning on the middle borehole location

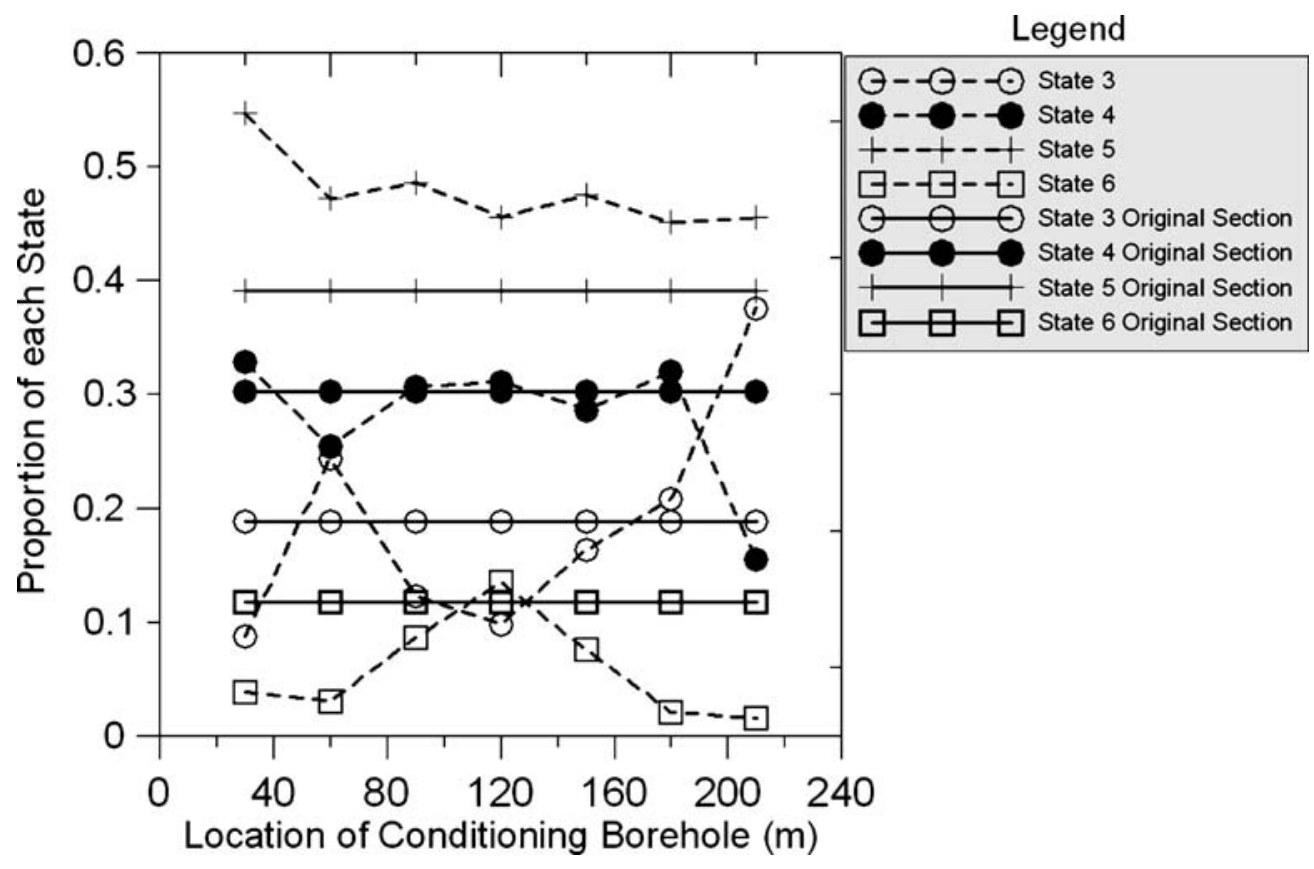


conditioning scenarios, layers can get disconnected leading to decreasing of the proportion of the same state. However, for more than 17 boreholes (15 m spacing), the convergence is monotone and reaches the proportion of the original section at 31 boreholes (8-m spacing) for all states. Effect of the borehole location on the geological configuration. Figure 11 shows the effect of conditioning on one middle borehole on the generated single realizations. The middle borehole is located at 30, 60, 90, 120, $150,180,210 \mathrm{~m}$ respectively. Qualitatively, conditioning on boreholes at 90,120 and $150 \mathrm{~m}$ seem to produce the best images when compared to the original one.

Effect of the borehole location on the indicator variograms. Figure 12 shows a quantitative measure "the indicator variogram of each state" for all images presented in Fig. 11. The figure emphasizes that boreholes at location 90,120, and 150 are the best to represent the original section. The exponential variogram is also plotted to illustrate the deviation from stationarity.

Convergence of the proportions of the states as a function of borehole location. Figure 13 shows the proportion of each state at different locations of the middle borehole. The borehole at location $120 \mathrm{~m}$ seems to be the best to capture the proportion of the states.

\section{Conclusions}

The following conclusions can be drawn,

1. The two-dimensional coupled Markov chain model could be successfully applied in reconstructing certain types of geology (sedimentary sequences with sharp facies boundary and directional tendency) under certain conditions (large scale) that might not be possible with a SIS/variogram combination.

2. CMC could easily take advantage of the soft geological information to estimate transition probability matrices, thus the number of hard data or observations could be significantly reduced for the simulation of geological structures.

3. A comparison between the sequential indicator simulation (SIS) used by Bierkens and Weerts (1994) and the coupled Markov chain model (CMC; Elfeki and Dekking 2001) shows more or less similar results in terms of the geological configuration of the confining layers when applied at the Gorkum area in the central Rhine-Meuse delta in the Netherlands. However, the CMC model has some merits over the SIS model. First, some parts of the confining layers are treated deterministically in the SIS method while this is not the case in CMC method. Second, non-stationarity in the confining layers was treated straightforwardly by CMC, while in the SIS model subdivision into three sub-layers had to be performed a priori, and three variogram models were used for each sub-layer, which is demanding on computer time and resources.

4. From variogram analysis, it is evident that variograms can be deceptive in modeling the spatial pattern and they reflect only part of the complete spatial structure in the field. The use of transition probabilities via the CMC model provides a somewhat better alternative approach, because it uses multiple point information.

5. The conditioning boreholes needed to capture the global variogram shape in the horizontal direction can be different from the number required for the vertical direction; the reason is related to the dominant geological features in the structure. In this case study, 5 boreholes were sufficient to capture the global variogram in the vertical direction while 25 boreholes were needed to capture the global variogram in the horizontal.

6. Reproduction of the global geological features requires a relatively small number of boreholes (in this case study, nine boreholes with $30-\mathrm{m}$ spacing over a distance of 240 $\mathrm{m})$. However, reproduction of proportions of each state requires a relatively large number of boreholes (in this case study, 31 boreholes with 8-m spacing over a distance of $240 \mathrm{~m}$ ).

7. Regarding the borehole locations, it was found (in this case study) that conditioning on a borehole that is located at $120 \mathrm{~m}$ is the best to capture the geological features and the proportion of the states.

Acknowledgement The authors would like to thank the two anonymous referees for their valuable comments on the manuscript.

\section{References}

Bierkens MFP (1994) Complex confining layers: a stochastic analysis of hydraulic properties at various scales, $\mathrm{PhD}$ Thesis, Utrecht University, Utrecht, The Netherlands, $263 \mathrm{pp}$

Bierkens MFP (1996) Modelling hydraulic conductivity of complex confining layer at various spatial scales. Water Resour Res 32 (8):2369-2382

Bierkens MFP, Weerts HJT (1994) Application of the indicator simulation to modeling the lithological properties of a complex confining layer. Geoderma 62(15):265-284

Carle SF, Fogg GE (1996) Transition probability-based indicator geostatistics. Math Geol 28(4):453-476

Carle SF, Fogg GE (1997) Modelling spatial variability with oneand multi-dimensional continuous Markov chains. Math Geol 29(7):891-918

Cross GR, Jain AK (1983) Markov random field texture models. IEEE Trans Patt Anal Mach Intell 5(1):105-117

Davis JC (1986) Statistics and data analysis in geology. Wiley, New York, $646 \mathrm{pp}$

Elfeki AMM (1996) Stochastic characterization of geological heterogeneity and its impact on groundwater contaminant transport. PhD Thesis, TU Delft, The Netherlands, Balkema, Lisse, $301 \mathrm{pp}$

Elfeki AMM (2006a) Prediction of contaminant plumes (shapes, spatial moments and macro-dispersion) in aquifers with insufficient geological information. J Hydraul Res 44(6):841-856

Elfeki AMM (2006b) Reducing concentration uncertainty using the coupled Markov chain approach. J Hydrol 317:1-16 
Elfeki AMM, Dekking M (2001) A Markov chain model for subsurface characterization: theory and applications, mathematical geology. 33(5):569-589

Elfeki AM, Dekking FM (2005) Modelling subsurface heterogeneity by coupled Markov chains: directional dependency, Walther's law and entropy. J Geotech Geol Eng 23:721-756

Elfeki AMM, Rajabiani HR (2002) Simulation of plume behavior at the Macrodispersion Experiment (MADE1) site by applying the coupled Markov chain model for site characterization. 14th International Conference Computational Methods in Water Resources "CMWR2002", Delft, The Netherlands, June 2002, Elsevier, Amsterdam, 655-662 pp

Galbraith RF, Walley D (1976) On a two-dimensional binary process. J Appl Prob 13:548-557

Gelhar L (1993) Stochastic subsurface hydrology. Prentice Hall, Englewood Cliffs

Gomez-Hernandez JJ, Srivastava RM (1990) ISIM3D: an ANSI-C three-dimensional multiple indicator conditional simulation program. Comput Geosci 16(4):395-440

Keshta NAR (2003) An application of stochastic models in groundwater pollution transport, MSc Thesis, Faculty of Engineering, Mansura University, Mansoura, Egypt, 145 pp

Krumbein WC (1967) Fortran computer programme for Markov chain experiments in geology. Computer Contribution 13, Kansas Geological Survey, Lawrence, KS, USA

Li W, Zhang C, Burt JE, Zhu A-X, Feyen J (2004) Two-dimensional Markov chain simulation of soil type spatial distribution. Soil Sci Soc Am J 68(5):1479-1490
Lin C, Harbaugh JW (1984) Graphical display of two and threedimensional Markov computer models in geology. Van Nostrand, New York

Park E, Elfeki AMM, Dekking FM (2003) Characterization of subsurface heterogeneity: integration of soft and hard information using multi-dimensional Coupled Markov chain approach. In: Tsang C-F, Apps JA (eds) Underground injection science and technology symposium. Berkeley, CA, October 2003, 49 pp

Proce CJ, Ritzi RW, Dominic DF, Dai Z (2004) Modelling multiscale heterogeneity and aquifer interconnectivity. Groundwater 42(5):658-670

Ritzi RW, Dai Z, Dominic DF, Rubin YN (2004) Spatial correlation of permeability in cross-stratified sediment with hierarchical architecture. Water Resour Res 40:W03513, DOI 10.1029/ 2003WR002420

Weerts HJT (1996) Complex confining layers: architecture and hydraulic properties of Holocene and late Weichselian deposits in the fluvial Rhine-Meuse delta, The Netherlands, PhD Thesis, Utrecht University, The Netherlands, 189 pp

Weissmann GS, Fogg GE (1999) Multi-scale alluvial fan heterogeneity modeled with transition probability geostatistics in a sequence of stratigraphic framework. J Hydrol 226:48-65

Weissmann GS, Carle SF, Fogg GE (1999) Three-dimensional hydrofacies modeling based on soil surveys and transition probability geostatistics. Water Resour Res 35(6):1761-1770

Zhang C, Li W (2005) Markov chain modeling of mutinomial landcover classes. GISci Remote Sens 42(1):1-18 